\title{
Expanded newborn screening in Puerto Rico and the US Virgin Islands: education and barriers assessment
}

\author{
Ana Morales, MS, CGC $C^{1}$, Andrea Wierenga, PhD ${ }^{2,3}$, Carla Cuthbert, PhD, FACMG ${ }^{2,3}$, \\ Stephanie Sacharow, MD, FACMG ${ }^{2,3}$, Parul Jayakar, MD, FACMG ${ }^{2,3}$, Darcy Velazquez ${ }^{1}$, \\ Jessica Loring, $M S^{4}$, and Deborah Barbouth, MD, FACMG ${ }^{2,3}$
}

\begin{abstract}
Purpose: The implementation of the expanded newborn screening panel of 29 disorders recommended by the American College of Medical Genetics in Puerto Rico and United States Virgin Islands is still in development or in early stages. Efforts in the territories are complicated by educational and resource barriers that generate a wide gap between the islands and the US mainland. Methods: To meet immediate educational needs, we conducted in-services for local newborn screening professionals. The efficacy of the educational intervention was measured by pre and posttest scores and a seminar evaluation. An assessment was obtained to document local newborn screening needs and barriers, with focus on human resources, intervention, language, social issues, education, and communication. Results: Statistical significance was found ( $P$ value $\leq 0.05$ ) between pre and posttest scores of the educational intervention. Needs and barriers associated with expanded newborn screening were also documented. Conclusion: Puerto Rico and United States Virgin Islands face different challenges in their implementation of expanded newborn screening. The data obtained in the present study serves as foundation for the development of public policy and long-term educational programs. Genet Med 2009:11(3):169-175.
\end{abstract}

Key Words: expanded newborn screening, education, social issues

P uerto Rico (PR) and the United States Virgin Islands (USVI; St. Thomas, St. John, Water Island, and St. Croix) are located approximately 1000 and 1100 miles off the coast of Miami, Florida (FL), respectively. ${ }^{1}$ Although the USVI were acquired in 1917, after Denmark sold the islands to the United States (US), PRs acquisition occurred in 1898 as a result of the Spanish American War. ${ }^{2}$ Although both PR and the USVI have a political status of unincorporated territory with control of internal affairs (unless US law is involved), unlike USVI, PR is a commonwealth with its own constitution.

At present, all US states and territories have laws addressing newborn screening $(\mathrm{NBS})^{3}$ but no uniform federal mandate exists. Thus, disorders screened, follow-up protocols, and services differ across states and territories. ${ }^{4,5}$ As a result, significant disparities occur. ${ }^{4}$ Moreover, despite populations of $108,708^{6}$ and 3.9 million, ${ }^{7}$ respectively, both USVI and PR have a capitation on Medicaid funds, which is related to fiscal deficit

From the ${ }^{1}$ Cardiovascular Division, Miller School of Medicine; ${ }^{2}$ Division of Medical Genetics, Department of Human Genetics, Dr. John T. Macdonald Foundation, Miller School of Medicine; ${ }^{3}$ Department of Pediatrics, Miller School of Medicine; and ${ }^{4}$ Epidemiology and Public Health Program, University of Miami, Miami, Florida.

Ana Morales, MS, CGC, University of Miami School of Medicine, Clinical Research Building, C-205, Room 1112, 1120 NW 14th Street, Miami, FL 33136. E-mail: amorales4@med.miami.edu

Disclosure: The authors declare no conflict of interest.

Submitted for publication June 7, 2008.

Accepted for publication October 25, 2008.

DOI: 10.1097/GIM.0b013e318193076f and a relatively low socioeconomic status, further complicating the provision of NBS services.

According to the National Newborn Screening and Genetics Resource Center (http://genes-r-us.uthscsa.edu/), as of August 2008, 35 states universally offer or legally require screening for the core panel of 29 disorders recommended by the American College of Medical Genetics (ACMG). ${ }^{5}$ This number will increase as more states come on board. Expanded NBS programs in USVI and PR are still under development or in early stages. Table 1 compares the screening programs in both territories.

PR began NBS in 1977 with screening for hemoglobinopathies. Since then, with an ever increasing yearly birthratecurrently at 60,000-PRs Hereditary Disease Program has detected 252 cases of abnormal hemoglobins (excluding heterozygotes), 233 cases of congenital hypothyroidism (CHT), 59 cases of phenylketonuria (PKU), 4 cases of congenital adrenal hyperplasia, and 2 cases of galactosemia (unpublished data). These figures are a function of the program's historical evolution, as screening for PKU, congenital adrenal hyperplasia, and galactosemia began in the 1990s. The screening program of PR consists of a centralized location where testing and follow-up clinics occur. Heel stick samples are collected in regional hospitals by trained nurses. The director is a boardcertified hematologist, who has led the program since sickle cell screening implementation. All screening, follow-up, and confirmatory testing is performed in the local screening center. A nurse and one or two administrative staff are responsible for locating screen positive infants and coordinating follow-up testing. Turn around time from the moment that samples are received to the confirmation of results is usually 10 days. In addition to the director and other hematologists, an endocrinologist and a board-certified medical geneticist are available to provide follow-up care to infants with screen positive results for endocrine or metabolic disorders, respectively. Currently, 98\% of newborns are screened in PR (unpublished data). A local laboratory with tandem mass (MS/MS) spectrometry equipment has been added to the screening center, as the program plans to implement the core panel of 29 disorders recommended by the ACMG. Centers for Disease Control proficiency testing for amino acids and acylcarnitines was passed at $100 \%$. Pilot studies for expanded NBS testing of amino acids, acylcarnitines, and biotinidase deficiency (unpublished data) are under way. Efforts to implement cystic fibrosis screening have not officially begun. Hearing screening occurs and as of this date will continue to occur independently of the NBS screening program.

USVI began NBS in 1987. The infrastructure of the screening center in USVI consists of several Department of Health locations. The program is led by a registered public health nurse, who has support from administrative staff. Since then, and encompassing the time when this study was conducted, samples were sent to Wadsworth, NY for analysis. Local laboratories, where technologists collect heel stick specimens before an infant is discharged from hospital nursery and prepare 
Table 1 Newborn screening programs in Puerto Rico and US Virgin Islands

\begin{tabular}{|c|c|c|}
\hline & Puerto Rico & US Virgin Islands \\
\hline Births & 60,000 & 1,200 \\
\hline Year screening began & 1977 & 1987 \\
\hline \multicolumn{3}{|l|}{ Disorders screened } \\
\hline Hemoglobinopathies & $X$ & $X$ \\
\hline CHT & $X$ & $\mathrm{X}$ \\
\hline Galactosemia & $\mathrm{X}$ & $\mathrm{X}$ \\
\hline PKU & $X$ & $\mathrm{X}$ \\
\hline $\mathrm{CAH}$ & $X$ & \\
\hline Homocystinuria & & $\mathrm{X}$ \\
\hline MSUD & & $\mathrm{X}$ \\
\hline G6PD & & $\mathrm{X}$ \\
\hline Newborns screened & $98 \%^{a}$ & $95-98 \%{ }^{a}$ \\
\hline Expanded newborn screening & Pilot stages & $\begin{array}{c}\text { No expanded NBS at the time of study in 2006. Currently sending samples } \\
\text { to Perkin-Elmer }\end{array}$ \\
\hline
\end{tabular}

these for send out to testing facility, are in the Roy Lester Schneider Hospital (St. Thomas) and the Juan Luis Hospital (St. Croix). Results were reported within 7 days to the NBS program director or the manager of computer operations/follow-up coordinator. With a yearly birthrate of 1200, USVIs Integrated Newborn Screening and Follow-up Program has detected 200 cases of abnormal hemoglobins (including heterozygotes) and seven cases of CHT. The program also screened for glucose 6-phosphate dehydrogenase deficiency, maple syrup urine disease, homocystinuria, galactosemia, and PKU, but no cases have been detected. Follow-up is initiated by the director, who reports the screen positive result to the nurse in charge of clinic in St. Croix, St. Thomas, or to a private physician. Nurses also become involved for follow-up. Care of affected infants is provided by local pediatricians; however, many families with affected infants migrate to PR or the mainland (unpublished data). Currently, 95-98\% of newborns are screened in USVI (unpublished data). USVI expanded NBS was launched in October of 2007, several months after this study was conducted. Samples are sent to PerkinElmer Genetics (perkinelmergenetics. com) for the company's screening and confirmatory testing of more than 52 conditions (unpublished data). Turn around time is usually 1 week.

Implementing expanded NBS is a costly endeavor. Moreover, the addition of new disorders, most of them of metabolic etiology, implies an increased need for professionals who are knowledgeable, not only about medical genetics but also about the biochemical phenotypes and treatment of conditions included in the recommended core panel, nutritional management, and genetic counseling. ${ }^{8}$ In addition, false positives are expected in NBS programs. ${ }^{9,10}$ Therefore, the psychosocial consequences of potential parent-child dysfunction and family anxiety that normally arise as a result of the required medical interventions or miscommunication between providers and parents $^{9-11}$ in the setting of unexpected risk for genetic disease, warrant a careful examination of each region's overall readiness to expand NBS.

The present study was designed to evaluate the degree to which NBS personnel and affiliated health care providers in PR and USVI are knowledgeable about the benefits and limitations of MS/MS technology in NBS, as well as medical, genetic, and psychosocial issues that are relevant to expanded NBS. Second, the study aimed to assess needs and barriers that must be overcome for the successful implementation of expanded NBS in both territories.

\section{MATERIALS AND METHODS}

\section{Program directors interview}

For the development of the collaboration, interviews were conducted in person (USVI) and over the phone (PR) with NBS program directors. This survey allowed the directors to rate the aspects of collaboration most valuable to their territory in terms of educational programs, resource availability, participating personnel, core competencies needed in an expanded NBS program, technical assistance, and training.

\section{Educational intervention}

The information collected from the program director's interview guided the design of the educational intervention. This took the form of a 1-day workshop that used the metabolic team approach as the theme. The workshops took place during April and May of 2006 in USVI and PR, respectively. These on-site educational interventions with Continued Education Units were provided to health care providers and staff involved in local NBS services. The presenters were the members of the metabolic team of the University of Miami Center for Medical Genetics, consisting of an MD certified geneticist, a $\mathrm{PhD}$ biochemical geneticist experienced in MS/MS, a metabolic nutri- 
tionist, and a genetic counselor. In PR, presenters also included a metabolic nutritionist from Emory University. The objectives included learning about the territories' current NBS program; principles of screening; relevant metabolic pathways; practical knowledge and skills for intervention and management; standardized methods for use in initial acute and long-term intervention; follow-up diagnostic testing guidelines; specific medical foods and dietary interventions; genetic counseling skills; and financial, legal, and social issues associated with expanded screening. A didactic session was followed by small group discussions with case presentations which continued to illustrate and use the concept of a metabolic team approach to dealing with positive NBS results. These case presentations were made by the groups of participants with guidance from a presenter. A resource manual was created using the ACMG ACT sheets ${ }^{12}$ and other sources, and was distributed among the small groups to assist participants during the case discussion. Presentations on MS/MS followed by a question and answer period ended the workshop in both territories. In PR, an additional session on MS/MS technology was included. The educational aspect of the workshop was assessed by 21 multiple choice questions distributed before (pre) and after (post) the educational intervention. Completion of the tests was voluntary. Where possible, because Spanish is a dominant language in PR, the language needs in PR were accommodated. For example, the didactic session was presented in Spanish and the small groups were headed by a participant who was bilingual. The efficacy of the educational intervention was measured by a seminar evaluation consisting of a Likert (1-5) (1, poor; 5, excellent) scale evaluation of seven areas, including objectives, speakers, learning aids, topics' relevance to clinical needs, academic level, opportunity for questions, and overall quality.

\section{Needs and barriers survey}

A barriers assessment survey was designed using a Likert scale of $1-6$ with a rating system (1, strongly disagree; 5, strongly agree; 6, no opinion) and an open-ended option for comments. The survey was conducted on the same day of the educational intervention and was distributed at the beginning of the seminar, along with the pretest (see above). Although the pretest was finished and returned before the intervention began, participants had the entire day to complete the needs survey, which was voluntary. The purpose of this assessment was to collect demographic information, assess current NBS attitudes and practices, and to identify needs and barriers regarding the implementation of expanded NBS. The survey specifically assessed the following NBS areas: NBS principles, sample collection, patient and information retrieval, human resources, sample management, confirmatory diagnosis, laboratory issues, intervention, follow-up procedures, infrastructure, administration and management, language, social, and educational issues.

\section{Statistical analyses}

Analysis only accounted for tests with matched identification numbers. The pre and posttests were analyzed by paired Student's $t$ test, reported as mean $\pm \mathrm{SD}$ and a $P$ value of $\leq 0.05$ was taken as statistically significant. Descriptive statistics such as frequencies were used to describe the data from the barriers assessment survey. The data were analyzed using statistical software STATA version 9.

All educational materials, assessments, and survey tools were designed by the project team. Institutional review board approval was obtained before the interventions.

\section{RESULTS}

\section{Program directors interview}

The participants of the educational intervention were identified by program directors as those most involved in the current programs, including personnel involved in sample collection, patient retrieval, and program administration. These assessments also revealed different main topics of interest in both regions. Although PR was more interested in learning about MS/MS technology and assistance, USVI was interested in education of clinicians in genetics and treatment of NBS disorders. PR anticipated an audience consisting mainly of nurses and laboratory technologists, whereas USVI anticipated an audience consisting of nurses and primary care doctors. The information collected from these preliminary interviews was taken into consideration in the design of the educational activities.

\section{Educational intervention}

A diverse group of physicians, nurses, laboratory technologists, and NBS staff $(N=60 ; 50$ expected from USVI; $N=99$; 115 expected from PR) attended. Fifty percent $(n=50)$ and $73 \%(n=44)$ completed both pre and posttests in PR and USVI, respectively. A paired $t$ test revealed statistical significance $(P$ value $\leq 0.05)$ between pre and posttest scores (Fig. 1).

The evaluations of the educational interventions in both PR and USVI revealed high satisfaction (average 4 of 5 on a Likert scale) and need for similar events. Open-ended questions requiring general comments uncovered two different recurrent themes in PR and USVI. In PR, more than half of participants would have preferred education and materials in Spanish. A recurrent theme in the evaluations from USVI was that many found website links provided in the NBS resource manual helpful.

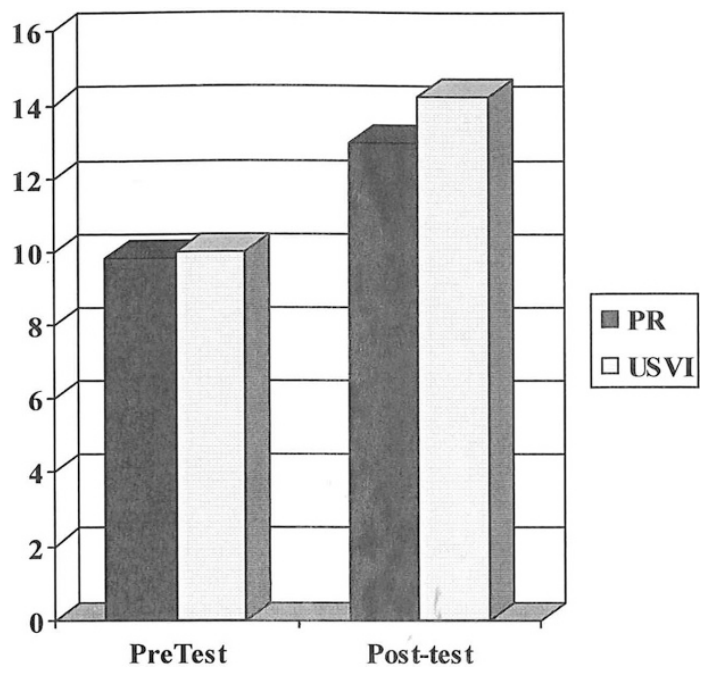

Fig. 1. Pre and posttest analysis of NBS knowledge. On the graph, black bars represent pre and posttest scores in Puerto Rico (PR). Gray bars represent pre and posttest scores in US Virgin Islands (USVI). Scores are presented as mean of results from 21 multiple choice questions. Paired $t$ test results show statistical significance between pre and posttest scores. 


\section{Needs and barriers survey}

\section{Survey participant characteristics}

Completed responses were received from 62 participants from PR (63\%) and 58 from USVI (97\%). As shown in Table 2 , most survey respondents were female (95\% PR; $86 \%$ USVI) with a nursing professional background (64\% PR; 57\% USVI). Most respondents (48\%) from PR had 16 or more of years of experience with NBS cases, whereas $53 \%$ of USVI respondents had 6 or more years of experience with NBS cases. The respondents were largely affiliated with hospitals or a government agency (Table 2). Results of selected areas of the needs and barriers survey are presented below.

\section{Attitudes toward NBS}

In both PR and USVI, 90\% agree that NBS is useful for public health planning. Similarly, $84 \%$ and $86 \%$ of respondents from PR and USVI, respectively, believe that all babies in all jurisdictions should be screened for the 29 disorders recommended by the ACMG. Conversely, $10 \%$ and $7 \%$ of respondents from PR and USVI, respectively, disagree that NBS is helpful for public health planning. The only comment made as to these statements, from a St. Thomas participant, provides clues about the existing barriers: "Private practice providers general [sic] refer to [the Maternal and Child Health] Program. To date, there is no indication for expanded screening in [Virgin Islands]. Cost versus benefits will have to be carefully evaluated. Follow-up services are not available locally (on-island). This is a major inhibitor of expanded screening." Regarding

Table 2 Demographic characteristics of 62 respondents from Puerto Rico and 58 from US Virgin Islands (USVI)

\begin{tabular}{|c|c|c|}
\hline & $\begin{array}{c}\text { Puerto Rico (\%) } \\
\quad n=62\end{array}$ & $\begin{array}{c}\text { USVI (\%) } \\
n=58\end{array}$ \\
\hline \multicolumn{3}{|l|}{ Gender } \\
\hline Female & 95 & 86 \\
\hline Male & 5 & 14 \\
\hline \multicolumn{3}{|l|}{ Profession } \\
\hline Physician & 13 & 14 \\
\hline Nurse & 64 & 57 \\
\hline Technologist & 15 & 5 \\
\hline Admin. Staff & 3 & 5 \\
\hline Other & 5 & 20 \\
\hline \multicolumn{3}{|l|}{ Place of employment } \\
\hline Hospital & 75 & 38 \\
\hline Private office & 1 & 5 \\
\hline Government agency & 10 & 43 \\
\hline Other & 14 & 14 \\
\hline \multicolumn{3}{|c|}{ Years of experience in NBS } \\
\hline 5 or less & 22 & 24 \\
\hline $6-15$ & 30 & 53 \\
\hline 16 or more & 48 & 23 \\
\hline
\end{tabular}

testing for the recommended core panel of 29 disorders, $10 \%$ of respondents and $14 \%$ of respondents from PR and USVI, disagree that such screening should be universal (Table 3).

\section{Human resources and management}

Data on human resources and management show that approximately $60 \%$ in PR and USVI think that there is not an appropriate number of trained genetics professionals. For both PR and USVI, cost of living was perceived as a deterrent for attracting clinicians to practice in their regions. However, the territories ranked other potential factors, such as culture and geography, in a different order, reflecting the greater language and cultural contrast between the US mainland and PR. In addition, data from the USVI reveals that $85 \%$ of respondents think that their NBS program does not have appropriate evaluation, performance monitoring, and quality assurance activities (data not shown).

\section{Medical intervention}

When asked about medical intervention issues, $15 \%$ and $26 \%$ in PR and USVI, respectively, indicated that they did not have access to information on the relevant metabolic pathway in their management of patients with an inborn error of metabolism. A similar percentage of respondents agreed with the statement "I have available resources for information on specific formulas and dietary interventions for the disorders tested for in our NBS program." In addition, among respondents from USVI, 24\% did not feel comfortable identifying a baby that is showing symptoms of a metabolic disorder (Table 4).

\section{Language barriers}

As the data from Table 5 show, both PR and USVI face language barriers in NBS management and care. In both PR and USVI, similar numbers were obtained when presented with the statements, "Language differences are an issue when finding information, gathering clinical information and patient education materials about NBS" and "Language differences are an issue when reading the information on the sample collection card." Differences were observed in answers to the statement "Language differences are an issue when establishing communication with other NBS programs," with 59\% and 39\% agreeing to the statement in PR and USVI, respectively.

\section{Access to health care, finances, and insurance issues}

Finally, participants who expressed an opinion (51\% in PR and $83 \%$ in USVI) agree that financial status and insurance

Table 3 Selected responses in percentages from participants' attitudes toward newborn screening

\begin{tabular}{|c|c|c|c|c|c|c|}
\hline & \multicolumn{2}{|c|}{ Agree (\%) } & \multicolumn{2}{|c|}{$\begin{array}{c}\text { Disagree } \\
(\%)\end{array}$} & \multicolumn{2}{|c|}{$\begin{array}{c}\text { No opinion } \\
(\%)\end{array}$} \\
\hline & PR & USVI & PR & USVI & PR & USVI \\
\hline $\begin{array}{l}\text { I think that NBS is useful } \\
\text { for public health } \\
\text { planning }\end{array}$ & 90 & 90 & 10 & 7 & 0 & 3 \\
\hline $\begin{array}{l}\text { All babies in all } \\
\text { jurisdictions should be } \\
\text { screened for the } 29 \\
\text { disorders recommended } \\
\text { by the American } \\
\text { College of Medical } \\
\text { Genetics }\end{array}$ & 84 & 86 & 10 & 14 & 6 & 0 \\
\hline
\end{tabular}

NBS, newborn screening; PR, Puerto Rico; USVI, United States Virgin Islands. 
Table 4 Selected responses from participants' needs and barriers assessment of medical intervention issues related to their local NBS programs

\begin{tabular}{|c|c|c|c|c|c|c|}
\hline & \multicolumn{2}{|c|}{ Agree (\%) } & \multicolumn{2}{|c|}{$\begin{array}{c}\text { Disagree } \\
(\%)\end{array}$} & \multicolumn{2}{|c|}{$\begin{array}{c}\text { No opinion } \\
(\%)\end{array}$} \\
\hline & PR & USVI & PR & USVI & PR & USVI \\
\hline $\begin{array}{l}\text { I have access to readily } \\
\text { available information } \\
\text { on the relevant } \\
\text { metabolic pathway in } \\
\text { my management of a } \\
\text { patient with an } \\
\text { inborn error of } \\
\text { metabolism }\end{array}$ & 63 & 25 & 15 & 26 & 22 & 49 \\
\hline $\begin{array}{l}\text { We have available } \\
\text { resources for } \\
\text { information on } \\
\text { specific formulas and } \\
\text { dietary interventions } \\
\text { for the disorders } \\
\text { tested for in our } \\
\text { NBS program }\end{array}$ & 74 & 37 & 14 & 22 & 12 & 42 \\
\hline $\begin{array}{l}\text { I feel comfortable } \\
\text { identifying a baby } \\
\text { that is showing } \\
\text { symptoms of a } \\
\text { metabolic disorder }\end{array}$ & 79 & 49 & 3 & 24 & 18 & 27 \\
\hline
\end{tabular}

Table 5 Responses from participants' assessment of language barriers related to their local NBS programs

\begin{tabular}{|c|c|c|c|c|c|c|}
\hline & \multicolumn{2}{|c|}{ Agree $(\%)$} & \multicolumn{2}{|c|}{$\begin{array}{c}\text { Disagree } \\
(\%)\end{array}$} & \multicolumn{2}{|c|}{$\begin{array}{c}\text { No opinion } \\
(\%)\end{array}$} \\
\hline & PR & USVI & PR & USVI & PR & USVI \\
\hline $\begin{array}{l}\text { Language differences are an } \\
\text { issue when finding } \\
\text { information, gathering } \\
\text { clinical information and } \\
\text { patient education } \\
\text { materials about NBS }\end{array}$ & 64 & 67 & 27 & 18 & 9 & 15 \\
\hline $\begin{array}{l}\text { Language differences are an } \\
\text { issue when reading the } \\
\text { information on the } \\
\text { sample collection card }\end{array}$ & 59 & 46 & 30 & 33 & 11 & 20 \\
\hline $\begin{array}{l}\text { Language differences are an } \\
\text { issue when establishing } \\
\text { communication with } \\
\text { other NBS programs }\end{array}$ & 59 & 39 & 32 & 32 & 9 & 29 \\
\hline
\end{tabular}

NBS, newborn screening; PR, Puerto Rico; USVI, United States Virgin Islands.

issues interfere with the success of the NBS program in their region (data not shown).

\section{DISCUSSION}

The results obtained from this study indicate that the implemented educational intervention is an appropriate short-term model for expanded NBS education. In addition, because the educational programs were designed based on assessments directed to NBS program directors, the seminars may not have necessarily targeted the educational needs of all NBS professionals in both territories. Despite this, the level of satisfaction of the respondents was high and their comments support the efficacy of this intervention. As expressed by a PR participant: "Offer more training 2-3 times per year to retrain ... doctors and nurses on the management of the cases in the presentation." Future research should be directed toward identifying specific content areas, previous training, and self-assessment of knowledge of all local NBS professionals, as well determining the impact on NBS providers' practice. Because the educational tools were used for the first time in the present study, repeated testing is necessary for validation and use in these and similar populations.

Although disparities in use of MS/MS and barriers for the implementation of expanded NBS have been documented (including USVI data), ${ }^{13}$ this study highlights findings that are unique to USVI and, for the first time, to our knowledge, documents similar barriers in PR. These barriers cover human resources, intervention, language, and financial issues in NBS. Several areas of attention are offered for discussion.

One of the most significant barriers uncovered by this study is the perceived need for qualified NBS providers. Cultural factors were ranked high as impediments to attract genetics professionals. As a respondent from USVI stated: "Availability [of NBS services] is affected by number of trained geneticists ... you have to love Island Life to be here. What's needed is good contact numbers and availability of back up."

The current number of trained biochemical genetics and counseling professionals is not adequate in PR or USVI. PR has one American Board of Medical Genetics (ABMG)-certified medical geneticist and no certified genetic counselors or trained metabolic nutritionists. Similarly, no certified medical geneticists, genetic counselors, or metabolic nutritionists are available in USVI. In these regions, the care of patients with metabolic disorders is provided by pediatricians and other health care professionals who have obtained some level of training and/or experience with these disorders.

Another human resources and management barrier is illustrated by our result that $85 \%$ of respondents reported that their NBS program does not have appropriate evaluation, performance monitoring, and quality assurance activities. In follow-up interviews with the Program Directors, evaluation, monitoring, and quality assurance activities are in place in both PR and USVI. However, it seems as if these plans are usually not part of the information provided to all parties. This might possibly reflect a lack of education or communication about what is done in their NBS program.

Generating an appropriately trained workforce should be a priority. We offer possible short-term and long-term solutions. Short-term goals include outreach clinics using mainland professionals. In this setting, outreach services, in person or by teleconference, by request of the regions would be offered. Similar outreach programs have been successful in NBS educational programs offered in developing countries. ${ }^{14}$

In addition to outreach programs, a territory-based geneticist employed by a US facility would serve as a liason between the islands and mainland providers. This approach has been successfully implemented in USVI, where the services of a pediatric neurologist, an uncommon specialty in this region, are funded by the Health Resources and Services Administration. Long-term goals include creating training centers, preferably in the US South East area, that provide cyclical courses, similar to Mayo Clinic's MS/MS training program. Working in collabo- 
ration with the $\mathrm{ABMG}$ and the American Board of Genetic Counseling, ABMG and/or American Board of Genetic Counseling-approved coursework, and rotations would be designed to provide training and relevant certification for bilingual and culturally appropriate medical practitioners, metabolic nutritionists, nurses, and genetic counselors. Because the training would be offered to working professionals with commitments in their land, a training of 2-5 years (as opposed to the 2-year fellowship or genetic counselor training) should be allowed.

To address the issue of apparent lack of appropriate evaluation, performance monitoring, and quality assurance activities, professionals involved in NBS should be encouraged to understand the purpose and direction of their programs. Communication within the program and with key players (such as nurses collecting samples in the hospital) can be fostered by means of newsletters, websites, teleconference, or ongoing local educational interventions. This will in turn create the basis for longterm interventions, which should be customized to fit the specific needs of each region.

Our study also revealed barriers associated with medical intervention. Improvement in this area will go hand in hand with an increased number of appropriately trained professionals and stakeholders. Access to health care, a common problem on the mainland, is complicated by Medicaid capitation in the territories. For example, in $\mathrm{PR}$, most patients have access to care through government-based health programs, which do not cover treatment such as medical foods. A minority has other types of insurance, which may provide access to better care. In USVI, most patients do not have insurance. Although USVI has not detected metabolic cases yet, these cases are expected to occur more often as a result of expanded NBS. In these cases, the Women, Infants and Children program will probably be used to provide special formula until 5 years of age. From discussions with NBS directors, many families try to access better care by migrating to the mainland and using available resources such as uncapped Medicaid. Given these findings, it would be reasonable to propose legislation to release additional Medicaid funding for NBS purposes in the US territories.

This study has a number of limitations. First, the barriers documented in this study represent only the perceptions of participants. Therefore, other barriers not identified by this study may be present.

Second, in PR there were 99 attendees; 50 completed both pre and posttests and 62 completed needs and barriers survey. In USVI, there were 60 attendees, but 44 completed both pre and posttesting and 58 filled out the needs and barriers survey. These differences may be explained by several factors. Both the pretest and the needs and barriers survey were distributed at the beginning of the seminar. Although the pretest was finished and returned before the intervention began, participants had the entire day to finish the needs survey, which was lengthy. The posttest was distributed at the end of the seminar. Given its voluntary nature and the different timing at which different materials were completed, it would be expected that not every attendee returned the materials. To encourage attendance at the workshop, both regions offered Continuing Education Units credits. Therefore, offering continued education credits may have encouraged many people to attend but not fully participate. Therefore, our results could be biased from a higher completion rate in USVI. In our experience, participants from PR needed more assistance, mostly in the form of translation to Spanish, to complete their materials. It would be reasonable to speculate that although the attendance rate in PR was higher than that in USVI, the response rate was lower given the language barrier. We would expect a higher completion rate in future educational interventions conducted in PR if Spanish is used as the primary language. Although nonresponder bias is a limitation of survey studies such as this, we think that a wide enough audience completed the program completely. Furthermore, the number of nonrespondents in PR may also support that language is a barrier.

Third, the primary language of the educational intervention and needs and barriers assessment was English. The assumption for PR was that both English and Spanish are considered official languages in $\mathrm{PR}^{7}$ and all postsecondary health care education and national certification is delivered in English. Despite accommodations made in PR (see "Methods"), language issues remained a recurrent theme across all PR-related interactions and interventions. This may have been a disadvantage, as stated by many PR participants in the evaluation: "The education was excellent; the problem I see is that it should all be in Spanish to get the most benefit." Thus, we conclude that the language barrier in PR is a limitation of this study, which may potentially decrease the validity of results obtained from this region. We speculate that language barriers may compound financial and human resources issues, potentially causing PRs NBS personnel to remain isolated from full integration in mainland-based regional genetics collaborations that include PR and USVI.

Ideally, professional education and social responsibility toward confirmatory diagnosis, treatment, and follow-up must be addressed before the implementation of expanded NBS in PR and USVI. This is of special concern in USVI, where, after this study, expanded NBS has been launched, at a time where none of the reported barriers have been overcome. For instance, shortage of medical professionals trained in biochemical genetics may have a negative impact on the successful implementation of NBS programs in the territories. The territories' perceived lack of experience with NBS deserves careful attention, as this barrier has been documented to be a factor contributing to missed cases of PKU and CHT in other regions. ${ }^{11}$

Implementing solutions to training needs and other documented needs and barriers in this study involve the provision of more funding. Given the historical, political, and infrastructural differences among the Islands (for example, PRs program being centralized, whereas USVI sends out samples), individually designed strategic plans are necessary. The NBS Saves Lives Bill should facilitate awarding grants for PR and USVI to provide screening, counseling, and health care services, as well as education and training in NBS and metabolic disorders to health care professionals and NBS laboratory personnel. Given the lack of resources to successfully compete for this funding, both program directors have asked for commitment in continued collaboration between the Florida team and the Islands to procure this kind of funding.

In summary, the prevailing attitude toward implementation of and education about expanded NBS in PR and USVI is positive, despite the lack of resources, both real and perceived. This positive attitude suggests that any carefully and strategically designed NBS implementation plan will be embraced once all the underlying resources are made available.

\section{ACKNOWLEDGMENTS}

The project team thank the South Eastern Regional Genetics Group (SERGG), the John T. Macdonald Center for Medical Genetics, SHS/Nutricia, Applied Biosystems, and Waters for funding and sponsoring of this project. We thank Phillys Acosta, DrPh and Emory University for their contribution and support. Special thanks to newborn screening program directors, Patricia Penn, RN and Pedro J. Santiago Borrero, MD, for 
their insights and significant contributions throughout the development of this project.

\section{REFERENCES}

1. World Atlas, 2008. Available at: www.worldatlas.com. Accessed April 18, 2008 .

2. Gispert C. Enciclopedia Estudiantil y de Puerto Rico, V5. Spain: Editorial Oceano: 1146 .

3. Therrell BL, Johnson A, Williams D. Status of newborn screening programs in the United States. Pediatrics 2006;117:S212-S252.

4. Howse JL, Weiss M, Green NS. Critical role of the March of Dimes in the expansion of newborn screening. Ment Retard Dev Disabil Res Rev 2006; 12:280-287.

5. Newborn screening: toward a uniform screening panel and system. Genet Med 2006;8(suppl 1):1S-252S.

6. Iglesias, I. Estados Unidos, Washington DC. In: Almanaque Mundial del 2006. Mexico: Editorial Televisa, 2005:108

7. Iglesias I. Puerto Rico, San Juan. In: Almanaque Mundial del 2006. Mexico: Editorial Televisa, 2005:149.
8. Tandem mass spectrometry in newborn screening. American College of Medical Genetics/American Society of Hum Genet Test and Technology Transfer Committee Working Group. Genet Med 2000;2:267-269.

9. Hewlett J, Waisbren SE. A review of the psychosocial effects of falsepositive results on parents and current communication practices in newborn screening. J Inherit Metab Dis 2006;29:677-682.

10. Tarini BA, Christakis DA, Welch HG. State newborn screening in the tandem mass spectrometry era: more tests, more false-positive results. $\mathrm{Pe}$ diatrics 2006;118:448-456.

11. Marsden D, Larson C, Levy HL. Newborn screening for metabolic disorders. $J$ Pediatr 2006;148:577-584.

12. Newborn Screening Act Sheets and Confirmatory Algorithms, 2006. Available at: http://www.acmg.net/resources/policies/ACT/condition-analyte-links. htm. Accessed March 26, 2008.

13. Feuchtbaum L, Faulkner L, Verghese S. Tandem mass spectrometry program implementation challenges for state newborn screening programs: national survey of barriers and issues. Pediatrics 2006;117:S253-S260.

14. Fukushi M. An international training and support programme for the establishment of neonatal screening in developing countries. J Inherit Metab Dis 2007;30:593-595. 